\title{
ELECTROCARDIOGRAPHIC CHANGES IN THE FIRST WEEK OF LIFE
}

\author{
BY \\ K. K. DATEY AND PILOO E. BHARUCHA \\ From the Departments of Cardiology and Padiatrics, K.E.M. Hospital and G.S. Medical College, Bombay, India* \\ Received April 24, 1959
}

Cardiac surgery has advanced so rapidly in the last decade that the correction of many congenital heart defects, which was the dream of the surgeon of yesterday, has today become a reality. This vastly extended scope of operative technique, which may indeed be life-saving in infants and children, can only be possible with accurate diagnosis. Though many special techniques are available for determining the exact nature of the defect before operation, none perhaps is so simple and affords so much information as the electrocardiogram, particularly as we shall see later, when serial records are taken at intervals after birth.

In the diagnosis of the abnormal, it is essential to be familiar with the normal, and it is curious that so far there is a dearth of reports of serial electrocardiograms of normal infants.

Richman and Master (1951) took serial cardiograms of ten babies from birth to four days. In the first 24 hours, the T wave was upright or diphasic in V4R, V1, and V2 and inverted in V4, V5, and V6 in 74 per cent of cases: it was negative in V1 in 7 per cent of cases. Ziegler (1951 and 1956) has taken about fifty cardiograms of babies from one to seven days, and has pointed out the characteristic patterns in the newborn, but how many of them were serial was not mentioned.

The variations in the normal patterns during the changing phases of infancy have not yet been established. This study was, therefore, undertaken to obtain data on cardiographic changes during the first week of life in normal babies.

\section{MATERIAl AND Methods}

In the present study, serial electrocardiograms were recorded in 44 normal babies from birth to seven days. On an average four records were taken in each infant, the first within 24 hours of birth, the second from one to three days, the third from three to five days, and the fourth from five to seven days after birth. In some cases five records were taken, one within half an hour, one between 12 and 24 hours after birth, and the others as already mentioned. There was no clinical evidence of cardiovascular disease in these infants.

All records were taken in the supine position, without sedation, on a single channel direct writing electrocardiograph, at a paper speed of $25 \mathrm{~mm}$. a second.

The standard extremity leads were recorded in the usual manner and the augmented unipolar extremity leads by Goldberger's technique (Goldberger, 1942). Unipolar præcordial leads were taken from V4R, V1 to V6, using the central terminal of Wilson (Wilson et al., 1934) as the indifferent electrode. These præcordial positions were localized with care, according to the recommendations of the American Heart Association.

The record was standardized in every lead to give a $10 \mathrm{~mm}$. deflection with the introduction of one millivolt into the circuit. A præcordial exploring electrode, $1.5 \mathrm{~cm}$. in diameter, was used. All precautions were taken to avoid distortion of ventricular deflections as a result of surface conduction by the careless application of excessive electrode jelly.

* Paper read at the III World Congress of Cardiology, Brussels, September, 1958. 
The heart rate was measured in each lead and the maximum, minimum, and average rates recorded. The amplitude of the different complexes, $\mathrm{P}, \mathrm{Q}, \mathrm{R}, \mathrm{S}$, and $\mathrm{T}$ was measured in each lead in all records. The mean electrical axis of $\mathrm{P}, \mathrm{QRS}$, and $\mathrm{T}$ waves in the frontal plane was determined by using the triaxial reference system of Bayley (1943). In a few cases, however, where the $T$ waves were flat in most leads, it was not possible to obtain the correct axis. These figures were, therefore, not included.

\section{RESUlTS AND DisCuSSION}

Heart Rate. The average rate in infants during this period is high (Table I), but is similar to the figures given by Furman and Halloran (1951), Ziegler (1951), and others. As no sedation was used, it is possible that the figures that were obtained in this group of infants were not basal and were possibly higher than the usual rates, as the procedure of taking the tracing would be sufficient to excite an infant.

TABLE I

HEART RATE IN 44 INFANTS

\begin{tabular}{c|c|c|c}
\hline \multirow{2}{*}{ Age in days } & \multicolumn{2}{|c}{ Heart rate (beats a minute) } \\
\cline { 2 - 4 } & Average & Minimum & Maximum \\
\hline $0-1$ & 131 & 88 & 162 \\
$1-3$ & 133 & 71 & 187 \\
$3-5$ & 134 & 94 & 172 \\
$5-7$ & 138 & 94 & 187 \\
\hline
\end{tabular}

TABLE II

Mean Electrical Axis of P, QRS, and T Waves

\begin{tabular}{c|c|c|c|c|c|c|c|c|c}
\hline \multirow{2}{*}{ Age in days } & \multicolumn{3}{|c|}{ P wave } & \multicolumn{3}{c|}{ QRS } & \multicolumn{3}{c}{ T wave } \\
\cline { 2 - 7 } & Average & Minimum & Maximum & Average & Minimum & Maximum & Average & Minimum & Maximum \\
\hline $0-1$ & 55 & 25 & 75 & 130 & 61 & 205 & 42 & -20 & 140 \\
$1-3$ & 53 & 30 & 80 & 124 & 65 & 180 & 52 & -10 & 140 \\
$3-5$ & 55 & 30 & 80 & 127 & 70 & 175 & 24 & -60 & 120 \\
$5-7$ & 54 & 19 & 80 & 128 & 80 & 171 & 24 & -60 & 120 \\
\hline
\end{tabular}

One interesting fact that emerged was that the average rate at the end of a week was about 7 beats a minute more than that at birth. This may be because the infant is a little more awake and active by that time. Ziegler (1951) also noted a similar rise.

Rhythm. Sinus arrhythmia was seen in seven infants, always at rates below 115 a minute. Out of the five who showed sinus arrhythmia at birth, two continued to show it even at 7 days; in two others it stopped after 24 hours when the rates increased to 138 and 162 a minute respectively; and in one it stopped after three days when the rate rose to 150 a minute. There were two others where sinus arrhythmia started after 24 hours: in one it disappeared on the seventh day and in the other it was still present at the end of the seven days.

Furman and Halloran (1951) found normal rhythm without sinus arrhythmia in 20 cardiograms in the first week of life, and Richman and Master (1951) found it in only 4 of 70 cardiograms. There is no doubt that sinus arrhythmia is uncommon in this age group (Gros et al., 1951). It is usually seen in older infants in whom the heart rate is slower (Ziegler, 1951).

Even with rates as high as 187 beats a minute sinus tachycardia was present. None of our cases had paroxysmal tachycardia, which, in infants, is usually associated with rates of 250 to 300 a minute. Hubbard (1941) found four reported cases of paroxysmal tachycardia and one of auricular 
flutter in babies under 10 days of age, and added another of his own, a baby of 10 days, who had supraventricular paroxysmal tachycardia.

Electrical Axis of Deflections in the Frontal Plane. The average axis of the $P$ wave at birth in our series was $55^{\circ}$ (minimum $25^{\circ}$, maximum $75^{\circ}$ ). There was no significant change in the average axis at the end of a week. These figures are similar to those reported by Ziegler (1951).

The $Q R S$ axis in the frontal plane varied between $61^{\circ}$ and $205^{\circ}$ at birth, with an average of $130^{\circ}$. In most cases there was little change in the axis at one week, except that when right axis deviation was extreme, it shifted towards the average at the end of a week. However, in a few cases the axis actually shifted to the right (Fig. 1).

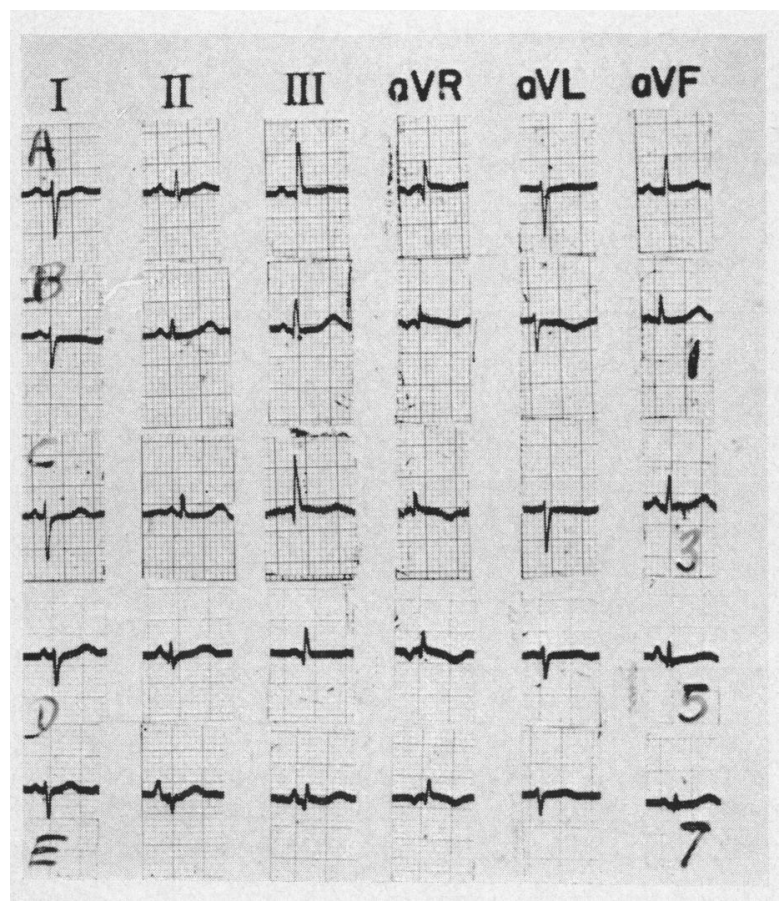

FIG. 1.-Serial electrocardiograms of a healthy full-term infant. The QRS axis in the frontal plane, initially $125^{\circ}$, changes over a period of 7 days to $170^{\circ}$. (A) at 30 minutes, (B) at 1 day, (C) at 3 days, (D) at 5 days, and $(\mathrm{E})$ at 7 days.

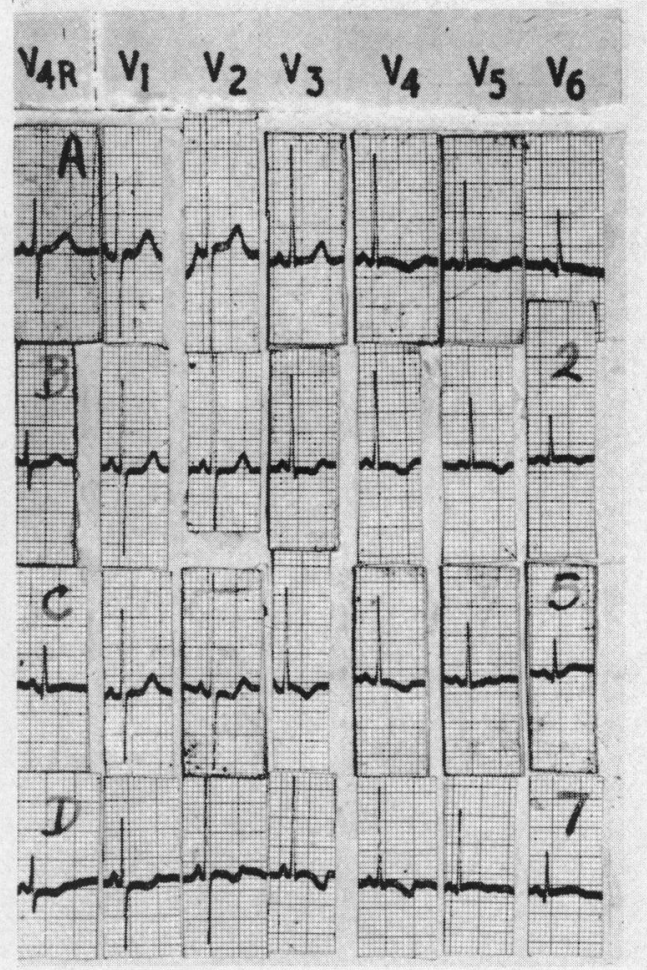

FIG. 2.-Serial electrocardiograms of a healthy full-term infant. $T$ waves in V4R and V1 to $\mathrm{V} 3$ are upright at 2 hours (A), become less positive at 2 days (B), flat at 5 days (C), and diphasic at 7 days (D). These are the usual $T$ wave changes seen in right præcordial leads.

There was a shift of the average axis of the $T$ wave to the left, from $42^{\circ}$ at birth to $24^{\circ}$ at one week. This is a reflection of the greater positivity of $\mathrm{T}$ waves in the left præcordial leads at the end of one week. The values for the axes of P, QRS, and T are only approximate, since they were not calculated by measuring the area.

QRS Patterns in Precordial Leads. In all electrocardiograms, the $\mathrm{R}$ wave was prominent in V4R and V1, and the R/S ratio was greater than one in these leads. The common types of QRS patterns seen in the right and left præcordial leads are shown in Table III. They did not change significantly at one week. The pattern of right ventricular dominance was always striking. This point is worth emphasis as it may be difficult to distinguish from a pathological right ventricular hypertrophy. 
TABLE III

QRS Patterns in Precordial leads at Birth

\begin{tabular}{lll|c|c|c}
\hline & & Right side & Transitional zone & Left side \\
\hline 27 infants & $\ldots$ & $\ldots$ & R or Rs & Usually V3 to V6 & r, rs, or qr \\
17 infants & $\ldots$ & $\ldots$ & R or RS & Usually V2 to V4 & qR, R, or RS \\
\hline
\end{tabular}

$T$ Wave Changes in the Pracordial Leads. In serial electrocardiograms the most significant changes in the præcordial leads were seen in the $T$ waves, and the QRS complexes remained essentially the same. There were two distinct types of changes in the $T$ waves.

(a) In the first, the T waves in V4R and V1, which at birth were either positive or diphasic (-+), became diphasic (-+) and finally negative at the end of one week in most cases (Table IV). Typical $\mathrm{T}$ wave changes in the right præcordial leads during the first week are shown in Fig. 2.

TABLE IV

T Waves in Pracordial Leads

\begin{tabular}{|c|c|c|c|c|}
\hline & & V4R & V1 & V6 \\
\hline $\begin{array}{l}\text { At birth } \\
\text { Positive } \\
\text { Diphasic }(-\ddot{+}) \\
\text { Negative } \quad . . \\
\text { Flat .. } \quad . .\end{array}$ & $\begin{array}{l}\ldots \\
\cdots \\
\ldots \\
.\end{array}$ & $\begin{array}{r}59 \% \\
29 \% \\
2 \% \\
10 \%\end{array}$ & $\begin{array}{r}64 \% \\
29 \% \\
0 \% \\
7 \%\end{array}$ & $\begin{array}{r}58 \% \\
20 \% \\
7 \% \\
15 \%\end{array}$ \\
\hline $\begin{array}{l}\text { At one week } \\
\text { Positive } \\
\text { Diphasic }(- \text {. } \\
\text { Negative } \\
\text { Flat .. }\end{array}$ & $\begin{array}{l}\ldots \\
\cdots \\
\ldots \\
.\end{array}$ & $\begin{array}{r}0 \% \\
29 \% \\
71 \% \\
0 \%\end{array}$ & $\begin{array}{r}3 \% \\
44 \% \\
53 \% \\
0 \%\end{array}$ & $\begin{array}{r}76 \% \\
10 \% \\
11 \% \\
3 \%\end{array}$ \\
\hline
\end{tabular}

In the left præcordial leads, the incidence of positive $\mathrm{T}$ waves increased, but in 11 per cent of cases the $T$ was still negative at the end of one week, so this cannot be considered abnormal. Fig. 3 shows negative $T$ waves in all præcordial leads at 7 days. These changes could possibly be on the basis of changes in serum potassium levels (Lepeschkin, et. al., 1958) or intraventricular pressure changes affecting the repolarization of the ventricles.

(b) The second $\mathrm{T}$ wave change in the right præcordial leads, V4R and V1, which has been noticed by us in three babies, has so far, to the best of our knowledge, not been described elsewhere. In these 3 cases, two electrocardiograms were taken within the first 24 hours, the first immediately after birth and the second after 12 to 24 hours. In the first case, the $\mathrm{T}$ wave changed from diphasic $(-+)$ to a more positive diphasic $(-++)$; in the second (Fig. 4), from negative to positive; and in the third (Fig. 5), from positive to more positive. Thus, in these three cases, there was a significant change towards positivity in the $T$ waves from birth to 24 hours. After 24 hours, the $\mathrm{T}$ waves followed the usual changes described in $(a)$.

These unusual $\mathrm{T}$ wave changes during the first 24 hours may be due to electrolyte changes or to an increase in oxygen saturation as the respirations improve. Hæmolysis of the red blood cells after birth may increase the serum potassium level, thus causing a positive $T$ wave. Clinically there was no respiratory embarrassment or cyanosis at birth in these three infants. However, no oxygen saturation studies were done, nor were the serum electrolytes determined, so it is not possible to express any opinion. 


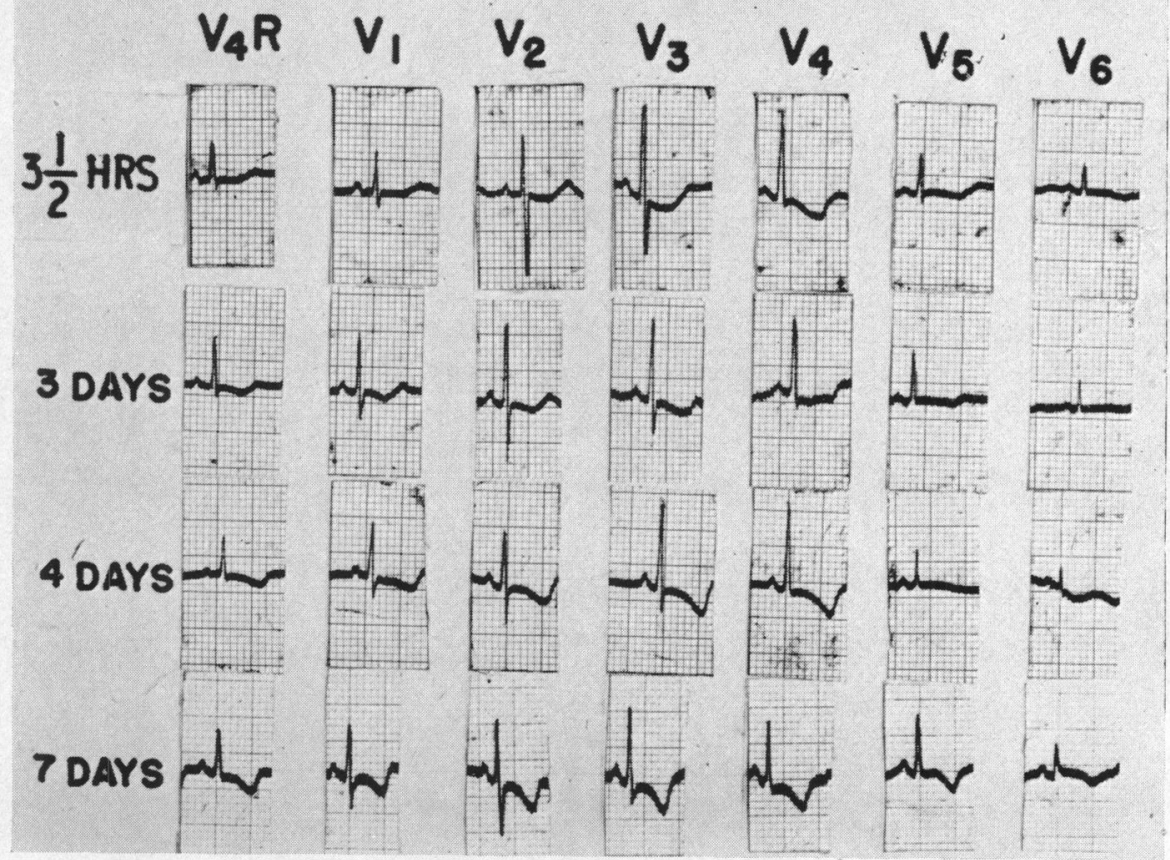

Fig. 3.-Serial electrocardiograms of a healthy full-term infant, showing the usual evolution of $\mathrm{T}$ waves in right precordial leads. They are positive at birth and become negative at 7 days. Here, however, the unusual feature is the presence of negative $T$ waves in all præcordial leads at 7 days.

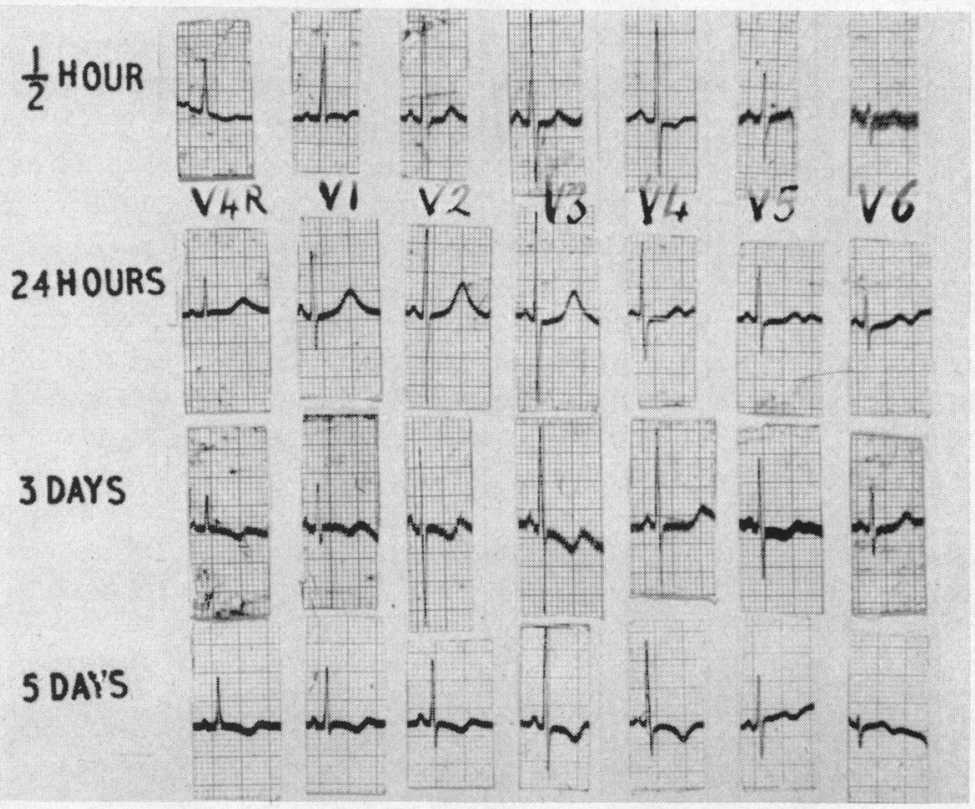

FIG. 4.-Serial electrocardiograms of a healthy full-term infant. T waves in V4R and V1 are negative at half an hour, become positive at 24 hours, and subsequently become negative at three and five days. 


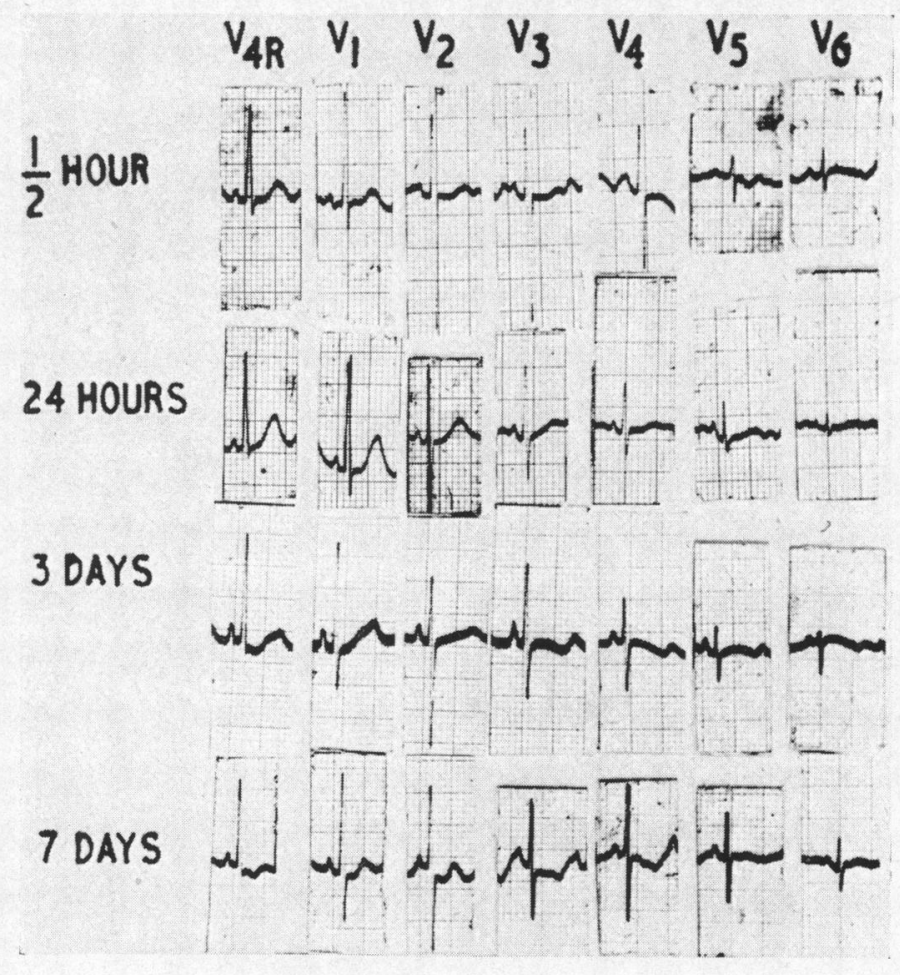

FIG. 5.-Serial electrocardiograms of a healthy full-term infant. $T$ waves are positive in right præcordial leads at birth. However, they become more positive at 24 hours, and subsequently become negative at seven days.

\section{SUMMARY}

Serial electrocardiograms were recorded in 44 normal infants, from birth to seven days of life, and changes noted therein are reported.

The average heart rate at birth was 131 beats a minute, and at 7 days 138 a minute. Sinus rhythm was present in all cases. 7 showed sinus arrhythmia at rates below 115 a minute.

At birth, the average axis for the $P$ wave was $55^{\circ}$ and for QRS, $130^{\circ}$. It did not change significantly at the end of one week. The average axis of the T wave shifted to the left, from $42^{\circ}$ to $24^{\circ}$.

All electrocardiograms showed R, Rs, or RS complexes in V4R and V1. The QRS patterns remained essentially the same at the end of one week.

Most significant changes were seen in the $T$ waves in the chest leads. Within 24 hours of birth, the $T$ waves on the right side in V4R and V1 were positive in 59 per cent, diphasic $(-+)$ in 29 , flat in 10, and negative in 2 per cent. At the end of 7 days, the $T$ waves became negative in 71 and diphasic $(-+)$ in 29 per cent. Unusual changes, which have not so far as we know been described, were seen in three cases. The $T$ waves in the leads from the right side became more positive within the first 24 hours. Subsequently they followed the usual pattern.

\section{REFERENCES}

Bayley, R. H. (1943). Amer. Heart J., 26, 769.

Furman, R. A., and Halloran, W. R. (1951). J. Pediat., 39, 307.

Goldberger, E. (1942). Amer. Heart J., 23, 483.

Gros, G., Gordon, A., and Miller, R. (1951). Peediatrics, 8, 349.

Hubbard, J. P. (1941). Amer. J. Dis. Children, 61, 687.

Lepeschkin, E., McKay, R. J., Poirier, and Starcheska, Y. K. (1958). III World Congress of Cardiology, Brussels.

Richman, B., and Master, A. M. (1951). Amer. Heart J., 41, 687.

Wilson, F. N., Macleod, A. G., and Barker, P. S. (1934). Amer. Heart J., 9, 447.

Ziegler, R. F. (1951). Electrocardiographic Studies in Normal Infants and Children. Thomas, Springfield. (1951). Circulation, 3, 438.

- (1956). Amer. Heart J., 52, 533. 